\title{
Gastroduodenal involvement as an unusual presentation of Crohn's disease
}

\section{Afectación gastroduodenal como presentación inusual de la enfermedad de Crohn}

Carlos San Miguel Méndez¹, María Jesús Álvarez Martín¹, Mónica Mogollón González Inmaculada Segura Jiménez ${ }^{1}$, Raquel Conde Muíño', Ángela Salmerón Ruíz ${ }^{2}$, Pablo Palma Carazo'

${ }^{1}$ Department of General and Digestive Surgery. Virgen de las Nieves University Hospital. Granada. Spain.

${ }^{2}$ Department of Radiology. Virgen de las Nieves University Hospital. Granada. Spain.

\begin{abstract}
It is relatively uncommon for Crohn's disease to implicate the gastric and duodenal regions and occasionally it can cause pyloric stenosis, in which medical therapy may be ineffective and surgery might be required. We report two exceptional cases with prepyloric stenosis secondary to Crohn's disease, aiming to emphasize the clinical suspicion and to describe the diagnostic imaging procedure and surgical treatments.
\end{abstract}

\section{Resumen}

Es relativamente infrecuente que la enfermedad de Crohs afecte al estomago y duodeno y ocasionalmente puede producir estenosis pilórica, en estas situaciones el tratamiento médico suele ser ineficaz y se requiere tratamiento quirúrgico. Se exponen dos casos clínicos excepcionales de estenosis prepilórica asociada a la enfermedad de Crohn, dirigidos a enfatizar en la sospecha clínica y describir el diagnóstico y el tratamiento quirúrgico
Keywords: Crohn's disease, gastroduodenal disease, gastric stenosis, enterography.

Palabras clave: la enfermedad de Crohn, enfermedad gastroduodenal, estenosis gástrica, enterografía.

\section{PATIENTS AND METHODS:}

Case Report 1: A 29-year-old woman, diagnosed with controlled ileocolonic Crohn's disease (CD) 7 years ago was admitted with abdominal pain accompanied by anorexia and weight loss (17Kg in a year).

An upper endoscopy (UE) revealed a gastric retention and pyloric stenosis, with an inflammatory appearance. The endoscope could not pass through. A biopsy was taken. Negative H.pylori test.

Because of the persistence of the symptoms, an endoscopic dilatation was performed up to $12 \mathrm{~mm}$ due to pyloric stenosis. Furthermore, a MRI enterography was also realized. It revealed important signs of gastric distension and significant reduction of the pyloric region's lumen and first duodenal portion (Figure 1).

Clinical deterioration progressed, leading to surgery. Findings showed gastric dilatation with hypertrophy of its wall, pre-pyloric stenosis and an apparently normal pylorus. A longitudinal incision was performed in the pylorus revealing a circumferential stenosis of the antrum 7-8 mm in diameter and a gastric wall hypertrophy with a characteristically "cobblestone" appearance. The mucosal defect was repaired and closed transversely using the Heineke-Mikulicz technique.
Case Report 2: A 52-year-old-woman diagnosed with ileocolonic CD 8 years earlier, and with a surgical history of several procedures at the ileum site, was admitted with postprandial vomiting, accompanied by a very significant and painful abdominal distension with no further intestinal transit alterations.

Transit studies with barium were conducted, showing an elongated shaped stomach. Moreover, slow emptying with important alterations in bowels' folds was assessed. The UE reported inflammatory stenosis in duodenum, unable to be traversed by the endoscope. Biopsies were taken, with results of intense nonspecific duodenitis. HP test (-). Adalimumab therapy was begun but within two months the patient started to show progressive clinical deterioration with postprandial vomiting and oral intolerance.

Due to pyloric stenosis, MRI enterography was not indicated and alternatively PET-CT scan was performed to rule out further $C D$ afectation. Metabolic activity was assessed at the colic framework (Figure 2).

Within a week, surgery treatment was scheduled performing a gastrojejunostomy, to bypass the gastroduodenal stricture.

\section{ACTUALIDAD M É D I C A www.actualidadmedica.es} (c) 2016.Actual.Med. Todoslos derechosreservados
Carlos San Miguel Méndez

Department of General and Digestive Surgery. Virgen de las Nieves University Hospital. Av. Fuerzas Armadas S/N. Granada, 18014. SPAIN

Phone::+34 655600488

Email: sanmiguel.carlos@gmail.com 


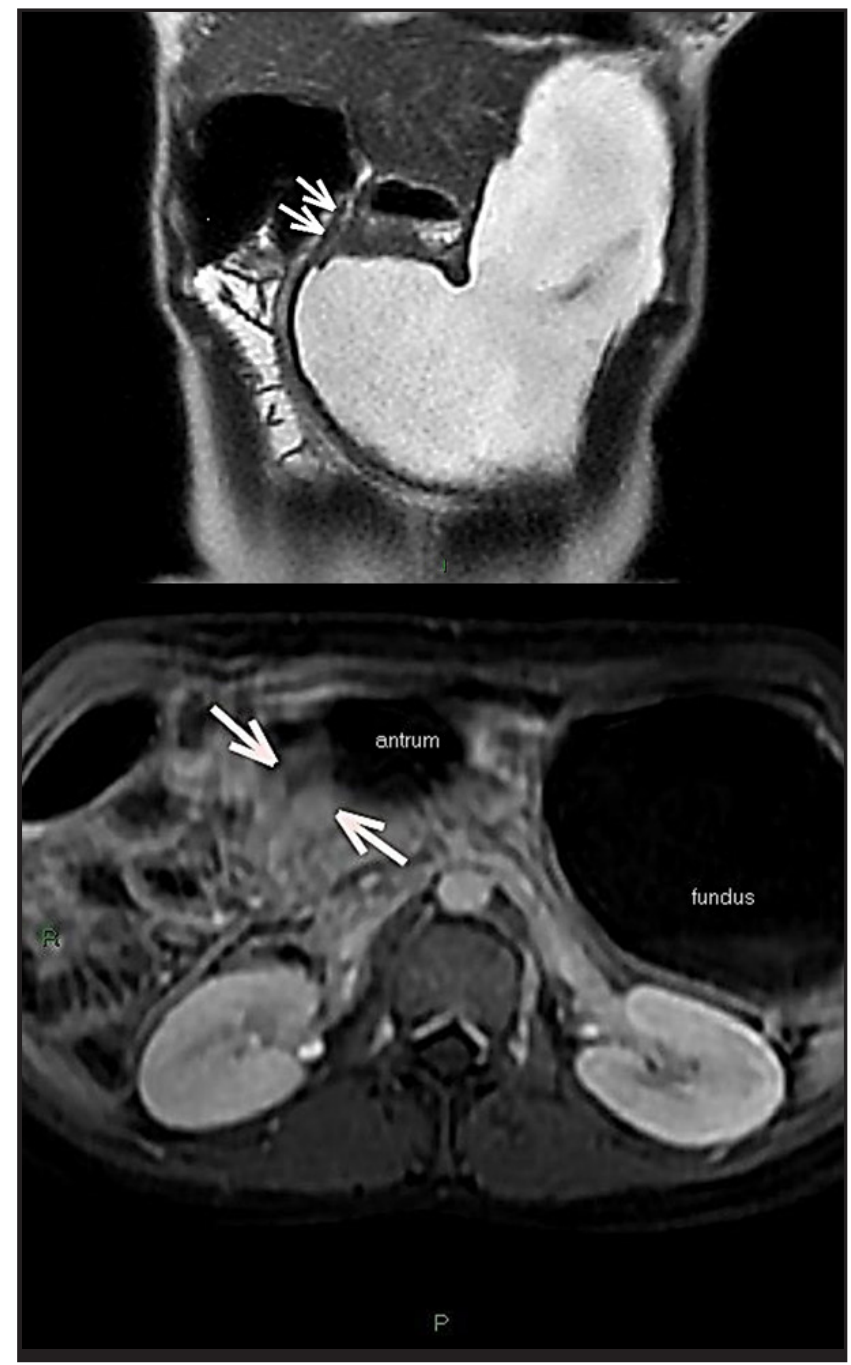

Fig 1. A. MRI Enterography. Important gastric distension and reduction of the lumen of the pyloric region and first duodenal portion. B. Axial MRI Enterography: Pyloric stenosis with unstratified homogeneous uptake.

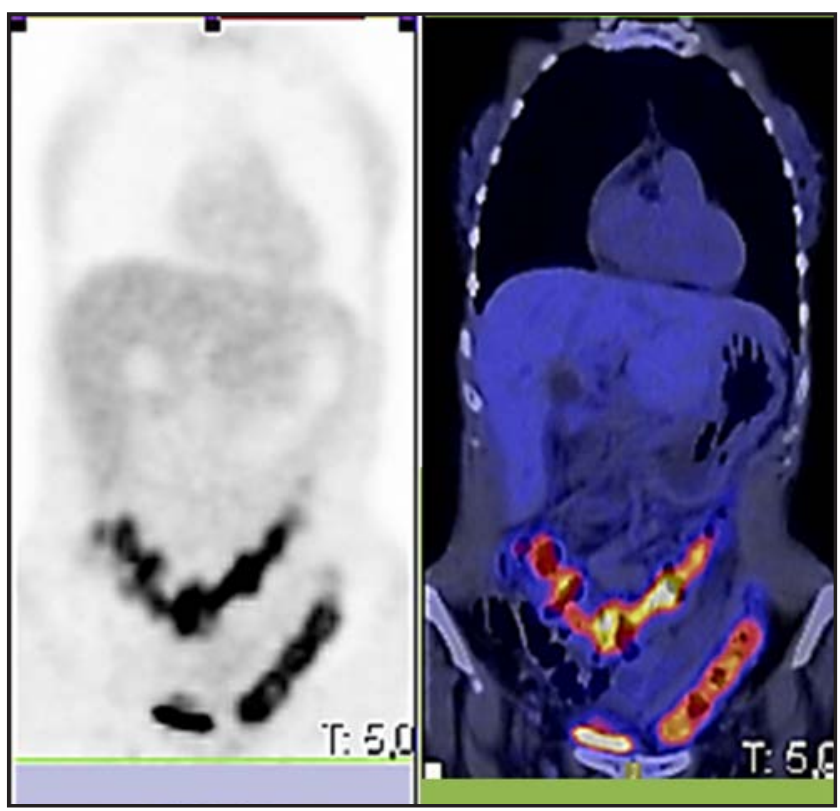

Fig 2. 18FDG-PET/CT: Increase of metabolism at the colic framework.

\section{RESULTS:}

The immediate post-operative course in the first case was uneventful and several months following discharge the patient continues with proper oral tolerance. Imaging studies upon ultrasound revealed no further passage impairment neither gastroduodenal nor ileal.

The Pathology report was described as fragments of moderate chronic non-specific inflammation, mild epithelial dysplasia and ulceration foci.

The post-operative period was also uneventful in our second case, and on the third day the patient started to drink liquids. She was discharged one week later with no surgical complications. During her follow-up consultations, there have been no symptoms or findings suggestive of relapse. Indeed, she has proper oral tolerance, having gained $6 \mathrm{~kg}$ weight.

Her mild affection at the colon frame is still objective upon colonoscopy but without any clinical manifestation.

\section{DISCUSSION:}

$C D$ can involve any part of the gastrointestinal tract; however, there are few reports on the pathology and treatment of gastric lesions in this disease, which led the interest of our case report.

Gastroduodenal involvement of CD is present in $30 \%$ of cases but being symptomatic in only $0.5 \%$ to $4 \%$ of them (1), and almost all have simultaneous affectation of the terminal ileum or large intestine, as in our cases $(2,3,4,5)$.

The most common symptom, epigastric postprandial pain, is usually relieved by food intake or antiacids. Continuous abdominal pain, associated with nausea and vomiting, weight loss, and anorexia, suggests difficulties in gastric emptying probably due to gastroduodenal stenosis (3). However, these symptoms may also be attributable to ulcer disease or treatment side effects, making the clinical suspicion and the ruling out very important. In this context, it should be underlined that the prevalence of $H$. pylori infection in these patients is similar to the general population $(2,3)$.

Histological findings may often be non-specific in $C D$ $(1,5)$, as in our two patients. Nevertheless, despite a clear history of inflamatory bowel disease, an UE biopsy is always recommended.

Traditional imaging in $C D$ has included ultrasound and CT. At present, magnetic resonance enterography provides excellent soft tissue contrast resolution, potential for dynamic assessment of the bowel, and lack of ionizing radiation (5), thus offering considerable information about disease extent, activity, and complications. The sensitivity of MRI to diagnose fistulae $(94.9 \%)$, abscesses $(93.8 \%)$, and strictures $(96.2 \%)$ supports its use as a superior imaging modality for complication assessment in $\mathrm{CD}$.

Unfortunately, pyloric stenosis does not allow an adequate bowel preparation, and thus could not be of interest in gastroduodenal stenosis of $C D$. In patients with $C D$, mucosal disease activity is routinely assessed by endoscopy and histologic evaluation, but in recent studies it has been evaluated the translational potential of noninvasive 18F-FDG PET/CT for the assessment of mucosal damage in $C D$, as we have done in our second case report (6). The usefulness of this method becomes relevant as an alternative to MRI enterography in the group of patients in which it is not possible to perform an adequate bowel preparation, as in our second case.

Approximately one third of all patients does not respond to medical treatment and requires surgery. Obstruction and gastric emptying difficulty are the most common indications (5). 
Gastric bypass mediated by gastrojejunostomy is the treatment of choice, although other options can be performed, including endoscopic dilatation, gastric resections, or stricturoplasty, as in our first case report $(1,4,5)$.

Although surgical results are satisfactory, early detection of these lesions and appropriate follow-up are cornerstones in preventing development of pyloric stenosis.

This report should alert gastroenterologists and surgeons about gastroduodenal involvement as an unusual presentation of CD.

\section{BIBLIOGRAPHIC REFERENCES}

1. Loftus EV Jr. Upper gastrointestinal tract Crohn's disease. Clin Perspect Gastroenterol 2002;5:188-191.

2. Costas H. Kefalas. Gastroduodenal Crohn's disease. BUMC Proceedings 2003;16:147-151.

3. Isaacs KL. Upper gastrointestinal tract endoscopy in inflammatory bowel disease. Gastrointest Endosc Clin North Am 2002;12:451-462.

4. Schill, G. Assessment of disease behavior in patients with Crohn's disease by MR enterography. Inflamm Bowel Dis 2013;19:983-90.

5. Allen BC, Leyendecker JR. MR Enterography for assessment and management of small bowel Crohn disease. Radiol Clin $\mathrm{N}$ Am 2014;52:799-810.

6. Lenze F, Wessling J, Bremer J, Ullerich H, Spieker T, Weckesser $M$, et al. Detection and differentiation of inflammatory versus fibromatous Crohn's disease strictures: prospective comparison of 18F-FDG-PET/CT, MR-Enteroclysis, and transabdominal ultrasound versus endoscopic/histologic evaluation. Inflamm Bowel Dis 2002;18:2252-2260. 